Bulletin d'Histoire Contemporaine de I'Espagne

$54 \mid 2020$

Les espaces du politique dans l'Espagne du Trienio liberal (1820-1823)

\title{
Santos Juliá (1940-2019)
}

José Álvarez Junco, Universidad Complutense y Madrid

\section{(2) OpenEdition \\ Journals}

Edición electrónica

URL: http://journals.openedition.org/bhce/3347

DOI: $10.4000 /$ bhce. 3347

ISSN: 1968-3723

Editor

Presses Universitaires de Provence

\section{Edición impresa}

Fecha de publicación: 1 enero 2020

ISSN: 0987-4135

Referencia electrónica

José Álvarez Junco, Universidad Complutense y Madrid, « Santos Juliá (1940-2019) », Bulletin d'Histoire Contemporaine de l'Espagne [En línea], 54 | 2020, Publicado el 01 julio 2020, consultado el 04 enero 2021. URL : http://journals.openedition.org/bhce/3347 ; DOI : https://doi.org/10.4000/bhce 3347

Este documento fue generado automáticamente el 4 enero 2021.

Bulletin d'histoire contemporaine de l'Espagne 


\section{Santos Juliá (1940-2019)}

\section{José Álvarez Junco, Universidad Complutense y Madrid}

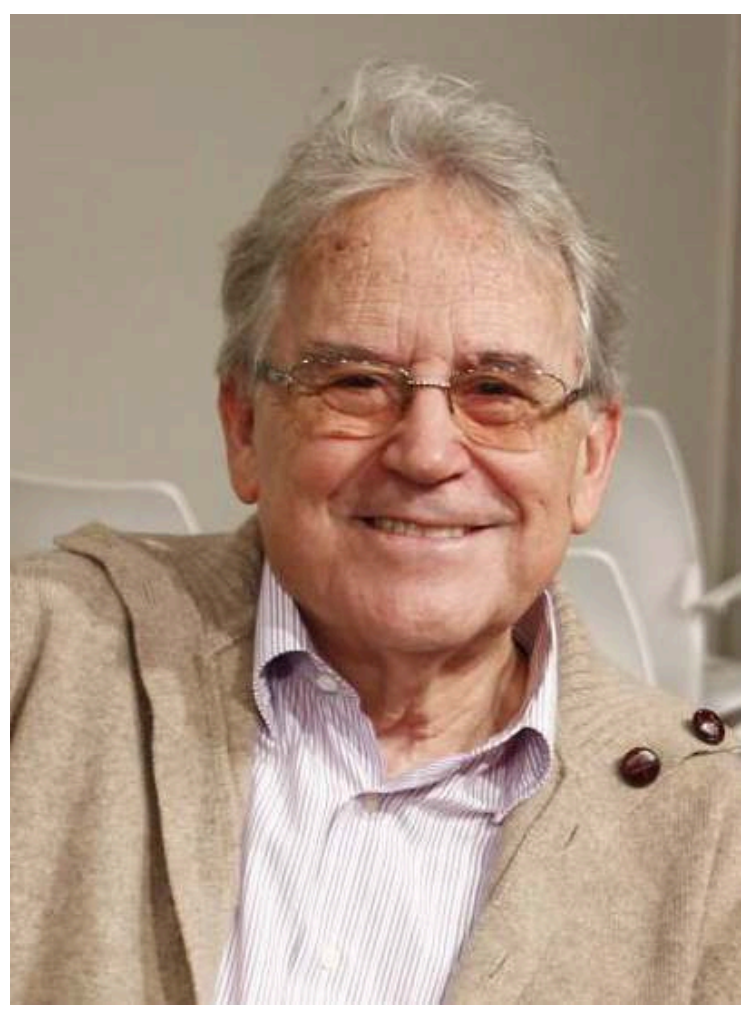

Era el mejor. Siento ser tan tajante. Mi cercanía a él y la inmediatez de las emociones ante su muerte deberían aconsejarme contener mis juicios. Pero justificaré lo que he dicho. No es solo que conociera infinidad de datos, que los conocía, sobre la España contemporánea. Es que tenía una idea guía, un esquema explicativo bien construido, que subyacía y daba coherencia a toda su obra. Si soy capaz de sintetizarla, esa idea consistía en que la construcción de un Estado que funcione es requisito esencial para la modernización y la democratización de una sociedad. Quizás él nunca la expuso de manera tan nítida y me temo que si me oyera me la rectificaría o matizaría mucho, pero ese creo que es el denominador común, la idea fuerza, de todo su trabajo. 
2 Santos Juliá era lo contrario del intelectual mediático, del tertuliano locuaz, que para llamar la atención se radicaliza hoy hacia la derecha y mañana hacia la izquierda. Tampoco respondía al modelo de nuestros abuelos, los de la Edad de Plata, envidiables literatos, maestros de metáforas, malabaristas de ideas, obsesionados con el "problema español”, campeones de propuestas de imposible aplicación práctica. Ni siquiera fue fiel a la cultura antifranquista, en espera siempre de la revolución, aunque su contenido y los sujetos llamados a realizarla hayan cambiado con los años.

3 No creo que traicione su posición intelectual si digo que su punto de partida era la defensa de la complejidad en la explicación del pasado. Los acontecimientos humanos nunca son sencillos, en todos los conflictos y los personajes hay luces y sombras, es preciso huir como del diablo de maniqueísmos y simplificaciones y, más aún, de deformaciones intencionadas al servicio de una causa. Lo que no tiene nada que ver con defender, asépticamente, que la responsabilidad de los crímenes o desastres recayera por igual sobre todos los protagonistas.

4 Porque en él tampoco era todo equilibrio intelectual, erudición o coherencia. Había un apasionado compromiso cívico. Defendía de forma nítida la democracia como principio de la legitimidad política en el mundo moderno; una democracia asentada no en el carisma popular, sino en un sistema de normas e instituciones, de libertades y derechos, de equilibrios y controles entre poderes. Por eso le interesó tanto la figura de Manuel Azaña, con quien se identificó, quizás en exceso. Porque Azaña no solo tenía excepcional lucidez y escribía primorosamente, lo que fascinó y fascinará siempre a quien se acerque a su obra, sino que creía en la democracia, en esa democracia institucional que defendía Santos. Aunque Azaña era un político que carecía, observaba él, de una estructura de partido y que confiaba demasiado en su palabra como única arma. Insobornablemente independiente, Santos Juliá no tuvo más lealtad que a sus propios principios, a su honestidad intelectual, a la que nunca traicionó. Por eso no era fácil la relación con él, porque contradecía con soltura, de manera natural, incluso a sus más cercanos. Una cosa era la amistad y otra consentir frivolidades, jugar con ideas que contradecían avances previamente logrados en la interpretación del pasado.

5 Santos Juliá inició sus investigaciones históricas analizando la crítica coyuntura vivida por el PSOE-UGT en 1934, cuando la izquierda caballerista dividió de hecho el movimiento en dos. Esa división de los socialistas, eje y fuerza hegemónica del republicanismo, fue, según él, uno de los problemas más graves de la República y condicionó el curso de la Guerra Civil.

6 Su interés se expandió luego hacia la Segunda República en su conjunto. Aquel fue un experimento democrático, el primero auténtico en la historia del país, instalado de la noche a la mañana en una sociedad mayoritariamente rural y carente de una clase media fuerte, pero que en los treinta años anteriores había dado un enorme salto y desarrollado una cultura urbana secularizada y moderna, ajena ya a controles clericales y caciquiles. La República no fue prematura ni casual, como su fracaso no fue inevitable. Pero el programa de reformas lanzado por los republicanos fue quizás demasiado ambicioso, teniendo en cuenta el débil aparato estatal con el que contaban para ponerlo en práctica.

7 La República, en todo caso, repetía Santos, debía ser estudiada en sí misma, no como mero preludio a la Guerra Civil. Y para entenderla no había que centrarse en las ideologías, en los discursos, en los grandes proyectos políticos o en sus supuestos protagonistas abstractos -el pueblo, el proletariado, la burguesía-, ni desde luego en 
ningún fatalismo racial, sino en las luchas diarias por el poder y en sus protagonistas concretos - partidos, sindicatos, instituciones, líderes-. Recuerdo bien cómo entendí todo el día en que le oí explicar la "entrega de armas al pueblo", decidida por el Gobierno republicano en respuesta al 18 de julio de 1936; no fue al pueblo, no, el pueblo no existe; las armas se entregaron a partidos y sobre todo a sindicatos, unos sindicatos que las canalizaron hacia sus miembros más radicalizados. Lo cual explica lo que ocurrió después: que no sirvieron para contener el avance de los sublevados, pero sí para emprender una despiadada «limpieza de fascistas» en la retaguardia; una serie de crímenes que desprestigiaron a la República y dificultaron el logro de apoyo internacional.

8 No es el momento hoy, o no me siento con fuerzas, para seguir desgranando sus ideas. Tras la historia del PSOE, la Segunda República y Azaña, escribió, sucesivamente, sobre otros muchos temas: la historia de Madrid, los intelectuales españoles en el XIX y XX, el debate sobre las dos Españas, el franquismo, la relación entre historia y memoria, la Transición... En conjunto, no es fácil catalogarle. No defendió ningún gran relato ni perteneció a ninguna escuela historiográfica. Prefirió analizar problemas concretos, nunca pequeños, para los que ofreció interpretaciones que huían de la simplicidad y el maniqueísmo: datos contrastados, explicaciones razonadas y ninguna tolerancia con metáforas y fuegos de artificio. Representó, como nadie, la historiografía española de la democracia, la posterior a la muerte de Franco, marcada por la crisis del marxismo, la reintroducción de lo político, la renuncia a esencialismos o metafísicas nacionalistas y la búsqueda de modelos y conceptos generalizables, válidos para diversos países y épocas; la profesionalidad, en definitiva. Es lo que representa hoy su escuela, porque a su alrededor, realmente, surgió una, y muy buena.

9 La muerte de Santos Juliá es una enorme pérdida para la vida pública, para todos los que seguían sus escritos, para los que tanto aprendieron, tanto aprendimos, de él. Qué harán, qué haremos, ante cualquier nueva situación difícil, ante cualquier conflicto futuro, sin su opinión, su coherencia, su solidez. Algunos hemos perdido un amigo entrañable. Todos, nuestra brújula, nuestro asidero más firme. 